\title{
Study on Structure of Inbound Tourism Network of Key Tourist cities in Henan Province
}

\author{
Junyuan Zhao \\ (Xin Yang university school of business , Xin Yang ,He Nan 464000 ,China)
}

\begin{abstract}
Keywords: Key tourist cities; Social network analysis; Tourism network; The spatial structure
\end{abstract}
\begin{abstract}
Using social network analysis method, on the basis of centricity model and the structure hole model, 9 key tourist city of Henan province inbound tourism space network node structure features and the overall structure of the corresponding study found that first entry tourism the key tourist city of Henan province with a total of 44 on the tourist flow relationship between network nodes, each of the key tourist cities exist between an average of 4.89 a tourist city with other tourist flow of agglomeration and diffusion, and 8.25 times the mediator role in tourism network; Second, Zhengzhou is the core of the inbound tourism network is the key tourist city of Henan province, Luoyang in the another core place, the rest of the key cities for the position is low, on the brink of inbound tourism network structure; Finally, the key tourist city of inbound tourism in Henan province overall network density is higher, but obviously there is not balanced, exist differences between different cities.
\end{abstract}

\section{Introduction}

As one of the six basic types of tourism activities defined by the World Tourism Organization, inbound tourism is a type of tourism activity which was developed earlier than the others in China, and its characters of development is different from domestic tourism. Inbound tourists have the features of large scale tourists' spatial behavior characteristics, they usually choose to carry on tourism activities either in places which own excellent tourist attractions or in cities which own the advantage of convenient transportation. Based on this spatial choice, the friction effect between spatial distances in tourist cities has little affection on destination choices of inbound tourists. The spatial organization and related form of major tourist cities constitute the basic framework of spatial macro inbound tourism. The spacial network effect of major tourist cities will not only have influence on the development of inbound tourism in the city itself, but also, on the integral development of regional inbound tourism industry. Therefore, it is meaningful to make researches on the spatial organization relation and spatial effect in major tourism inbound destinations.

In the early phase, the research on spatial network structure in inbound tourism destinations is based on the accessibility of transport networks between inbound tourism destinations, but the accessibility of transport networks is not accordant to inbound tourists' spatial behavior, which result in the error and onesidedness. There are big differences between the connection of tourism flow and traffic flow, especially the inbound flow connection show the jumping characteristics of flow, therefore it can reflect the dynamic characteristics and tourism preferences when making destination choices through carrying out researches on network structures of inbound tourism in major tourism cities in medium of tourism flow, it can reflect characteristics of inbound tourism related network structures in cities at the same time, manifest the function difference of regional inbound network in different cities. However, making researches on characteristics of inbound tourism related network can manifest the spatial fractal and analysis of inbound tourism development in tourism cities, which will lay a foundation for optimizing, regulating and controlling inbound tourism network structure. Therefore, researches on above issues are meaningful to the development of regional inbound tourism products, route design and regional inbound tourism cooperation.

However, researches on city tourism flow are mainly concentrated on the major aspects, such as structure, scale differences and city agglomeration tourism spatial structure ${ }^{[1-5]}$. Researches on urban inbound tourism are mainly focused on hot spot cities inbound tourism flow time and space 
dynamic model, the diffusion of city inbound tourism flow, time and space balance and spatial effect and so on ${ }^{[6-12]}$. But researches on inbound tourism flow in Henan province are very rare, and it is hardly to find researches on the network structure of inbound tourism flow in Henan province. Based on fractal theory, Xunsheng Ding, yongwen Li conducted researches on the hierarchy organization of inbound tourism flow in Henan province ${ }^{[13]}$, while Junyuan Zhao carried out researches on time and space revolution of inbound tourism flow in Henan province ${ }^{[14]}$, except this, Xinhui Zhan did researches on the coupling degree between inbound tourism flow in Henan Province and regional economic development ${ }^{[15]}$. Lijuan Meng conducted related research on tourism flow and factors which affect the destination coupling among the city of Zhengzhou, Kaifeng and Luoyang ${ }^{[16]}$. Based on the above research status, using social network analysis method in sociology as reference, this paper utilized quantitative research method to carry out researches on the structure of inbound tourism space related network in major cities in Henan province, and propose optimized strategies based on this, which will have practical guiding significance.

\section{Research Method}

The research on network structure by the method of social network analysis is mainly focused on two dimensions, which are network node and integrate network. Therefore, the research on the network structure of inbound tourism flow in major cities in Henan province mainly apply for these two dimensions, also mainly manifest on the integral research of network node structure and the integral network structure.

Structure Analysis Index of Tourism Network Node. The structure analysis index of inbound tourism network node mainly includes two models, which are centrality and structure holes, which are utilized to reflect the structural characteristics and importance of node in tourism network

Centrality model. Node centrality is an important structural position index of tourism network node, can reflect the function and status of node in tourism destination network. Centrality can be divided into three categories in general: extent centrality, intimate centrality and intermediary. These three different kinds of indexes have different meanings, extent centrality explains the node which are in the important central status in tourism destination network. Approach centrality index show the extent of distance between one tourism network node and the others, practical meaning can be expressed by the reciprocal of sum of shortest distance between this node and the others. The smaller of the value of approach centrality index, the higher of the approach centrality of this node, which means that the relation between this node and the others is more intimate. Intermediary centrality index means that the ability to be an intermediary for a tourism network node, actually it is lying on the important position of the shortcut between two nodes, the higher node of the intermediary centrality will get more tourism flow chances, gain abundant "intermediary benefits".

Structural hole model. The phenomenon of disconnection or linkage interrupt between tourism spatial networks nodes will exist, based on this situation, structural hole is used to express the disconnected place between tourism network nodes. There are many structural hole positions around one node, which means it can "intermediate" more tourism flows from other tourism nodes, therefore occupy a relatively small but replaceable position; but because of the shortage of replaceable node and tourism flow route, the tourism bottleneck will be formed, at this time redundancy and binding will be used to measure structural hole.

Redundancy is the loop issue of tourism flow, used to test if the replaceable phenomenon exist and the fluency of connection between nodes. Efficiency has an inverse relationship with node redundancy. The lower the efficiency, the higher the node redundancy, the competitive power is relatively low. The other index to measure structural hole is binding, which manifest the intense of one tourism network node rely on the others directly of indirectly. Therefore, on the one hand, the measurement of structural hole need to gain the extent of connection between some node and the others by means of efficiency, on the other hand, get the extent of one node relays on the other by means of binding. Furthermore, analyze the efficient connection and extent of dependence comprehensively between one node and the others, based on this, confirming the level of structural hole of according nodes. 
Integral Structural Analysis of Tourism Network. Network density Network density means that in tourism destination networks, practically existed relation quality divided by possibly existed the maximum connection quality in theory. Its calculation formula is ${ }^{[3]}$ :

$$
D=2 \sum_{i=1}^{n} d_{i}\left(n_{i} / n *(n-1)\right), \quad d_{i}\left(n_{i}\right)=\sum_{j=1}^{n} d_{i}\left(n_{i}, n_{j}\right)
$$

In the formula, $\mathrm{n}$ stands for the number of travel network node. If the two nodes $\mathrm{I}$ and $\mathrm{j}$ have a connection, then di $(n i, n j)=d i(n i, n j) 1$, otherwise, di $(n i, n j)=0$. The higher the tourism destination network density, the more nodes connection in network, the more tourism network functions are perfect and more clear.

Network Centralization. Network centralization is the indicator to measure the whole tourism network landscape center degree or trend of an area. And we use it to reflect the equilibrium degree of tourism network development. It id similar to centricity and also can be divided into Degree of Centricity, Close Centricity and Intermediary. This centricity models calculation are calculated by using the method of corresponding node centricity. Its basic ides is to find the biggest centricity value of each network nodes first, then work out the difference between this node and other nodes in network. Then sum up them. Then divide the greatest possible value of the network centricity difference sum which is composed of these nodes random ${ }^{[17]}$. The greater the centricity of tourism network map, the greater the centricity difference of each nodes in network.

\section{Inbound Tourism Spatial Correlation Network Build of Henan Key Tourist Cities}

The Choice of Key Tourism Cities. Combined with the tourist spatial behavior law, inbound tourists generally choose a city which has well known or high grade scenic as a tourist destination in destination choice. This study chooses 9 key tourist cities in Henan province as the object. They are Zhengzhou, Luoyang, Kaifeng, Anyang, Jiaozuo, Nanyang, Shangqiu, Pingdingshan and Zhumadian. The choice of key tourist cities mains consideration based on three aspects. One is the world heritage sites and scenic city, including Zhengzhou, Luoyang and Anyang. There is the visited object of inbound tourists due to the nature of the world heritage. Second is the ancient capitals and famous historical and cultural city, mainly including Zhengzhou, Luoyang, Kaifeng, Anyang, Nanyang and Shangqiu. Four of them are old and all of them are historical and cultural cities. The influence is extremely high. So they are the main cities of radiation large scale tourist spatial behavior. Third is the located city of 5A scenic spots which are the highest grade in Chinese scenic spots and are the main force of reception of inbound tourism. Those 9 located cities of 5A scenic spots also are the main destination of reception of inbound tourism in Henan province.

Data Acquisition. Inbound tourists including foreign tourists and Hon Kong, Macao and Taiwan tourists. In proportion of Hon Kong Macao and Taiwan are the largest. Followed by are Japan, South Korea, Malaysia, the United States, Germany, France and Russia. In order to the scientific of this study, we took the top ten countries and regions as the research object of inbound tourism in Henan as well as in Hon Kong, Macao and Taiwan. By using social network analysis method to study key tourist cities inbound tourism network, we need to get the flow data of it in different cities. So, we designed the corresponding questionnaires. There are tourism motivation, manner, line and times of inbound tourists and sociology characteristics of demographic and other related content. Among them, set cities for the tourist route nodes, in design of the problem has listed 9 key tourist cities of Henan and one "other city" option.

According to the needs of research and reality conditions, the research mainly in Zhengzhou, Luoyang, Kaifeng, Anyang, Jiaozuo. Considering Zhengzhou is the national transport hub and the tourist mid-turn destination, also is a large scale tourist traffic together place. So the main research in Zhengzhou and the rest as a supplementary investigation. Investigation period from December 2016 to January 2017, each city's research time is about one week.

Research site is the city's main traffic node(airports, high-speed), the core scenic area, etc. adopted random sampling method to obtain sample data and asked the staff involved in the research 
on "travel roads", the item of the fill in case to improve the effectiveness and credibility of the questionnaire.

By the statistics, the process sent 5000 questionnaires in total. 4632 effective questionnaires were taken back, and the effective rate was 92.64\%. in the final data sorting, eliminated the questionnaires which showed only visit to one city, only remained 3178 effective questionnaires.

According to the order and the number of the 9 major cities people who were choose by the inbound tourists travel routes. We established a vector data based of tourist flow and get a $9 \times 9 \mathrm{zij}$ matrix. On the basis of the matrix, we made a binarization processing by using the segmentation value and get the OBJ matrix which presents the directed 1-mode network of the tourist flow relationship between the 9 key tourist cities. Then, use software to paint the network structure map of inbound tourism destination in Henan.

The Analysis of Sample Structure. From the analysis of effective sample data in our investigation, we can see that the number of make inbound tourists accounted for $61.3 \%$ of the total while women account for $38.7 \%$ in Henan inbound tourists. The index of the number of traveling times in Henan show that the first time to travel inbound tourists accounted for $67.9 \%$. The second time to come accounted for $11.8 \%$, visited three times and more that three times accounted for $20.3 \%$. The proportion of the inbound tourists who first time to Henan is significantly higher than the re-traveler. For tourism purpose, inbound travelers who for sight seeing in Henan accounted for 46.7\%. $10.5 \%$ for leisure vacation, $18.6 \%$ for business meetings. $15.8 \%$ for visit friends and relatives. The rest $8.45 \%$ are for other purposes. The individual tourists of Henan inbound tourism accounted for $78.5 \%$ while team tourists whose traveling routes were arranged by the agency accounted for $37.1 \%$ of the total. $28.9 \%$ were arranged for official duties. Other ways accounted for $5.9 \%$.

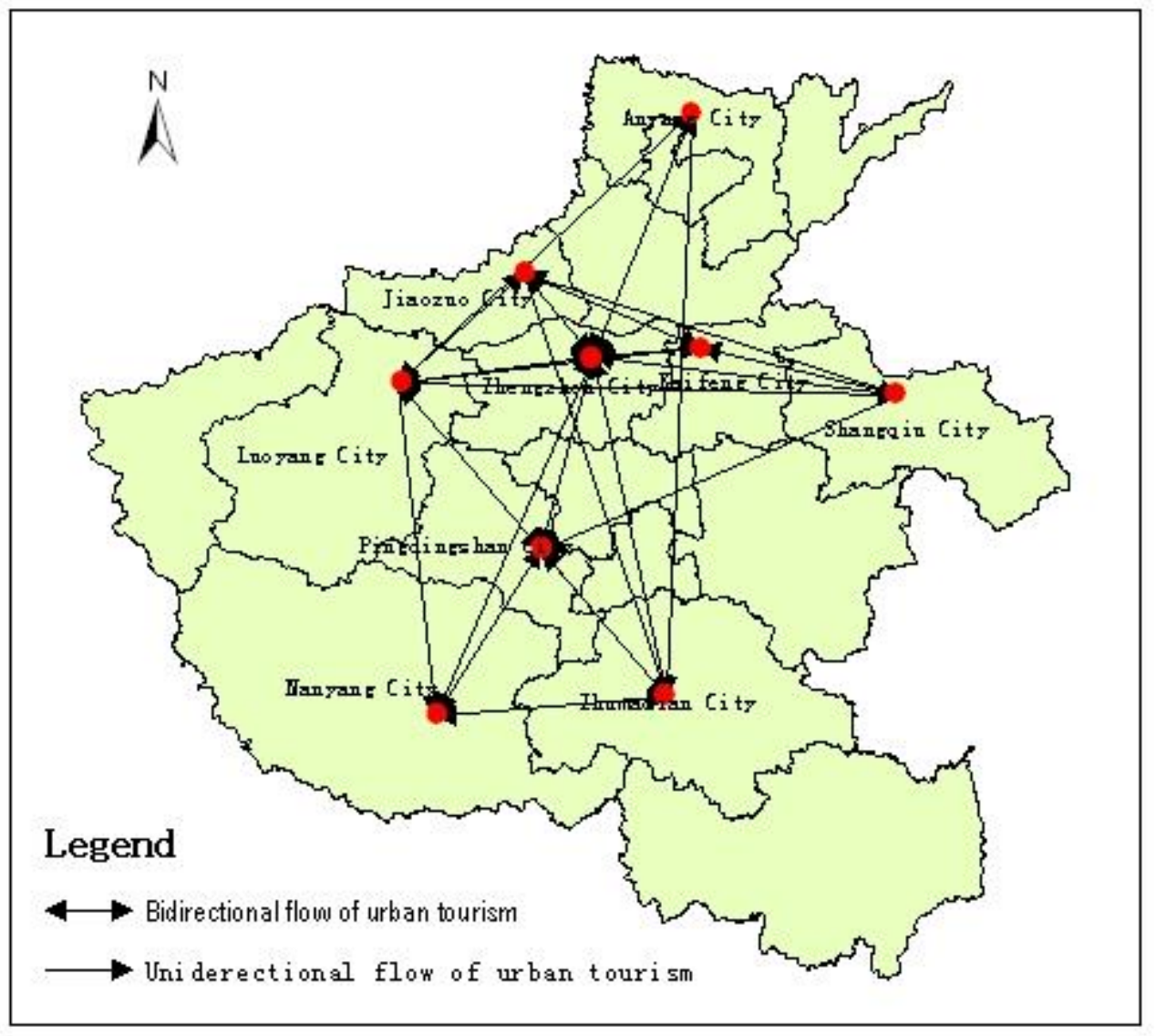

Fig. 1 Inbound Tourism Network of KeyTourist Cities in Henan Province

The Construction of Inbound Tourism Spatial Correlation Network in Key Tourist Cities of Henan Province. The inbound tourism spatial correlation network's building of the key tourist cities in Henan. According to the sampling survey of the tourist flow vector data between the key 
tourist cities, we built a network tourist flow numerical matrix of tourism destination. In order to facilitate to build a binary matrix, we need to choose a suitable segmentation value. The choice of segmentation value is random but must pass the initial sensitivity test to get the most suitable one finally. In order to prevents network connection appear full, smallest or rarely coupling show the typical network matrix, finally uses the " 10 " as segmentation value. When the tourist flow contact amount between the two node cities is more than 10 , sting it to 1 . Otherwise, set it to 0 . Used software, mapped the inbound tourism flow network of the 9 key tourist cities of Henan, shown in figure 1. In this diagram, each node represents a key tourism city, arrow pointing in the direction indicated that there has the tourist flow between one city and another city. The direction of arrow presents the tourist flow direction. There have a attachment from the node Zhengzhou to the node Luoyang, shows that the tourist flow contact amount is more than 10 and with a certain scale of tourist flow which spread from Zhengzhou to Luoyang. All of this can show that there is a tourist flow connection between the two modes. We can see clearly from the table that Zhengzhou and Luoyang have more relatively flow connection with other cities while other cities are relatively few.

\section{Structure of Inbound Tourism Network of Key Tourist Cities in Henan Province}

The Node Structure of Inbound Tourism Network of Key Tourist Cities. Using the node centrality and the structural hole analysis indicators, we get the inbound tourism network node structure of 9 key tourist cities in Henan. Specific values as shown in table 1. Overall, there are totally double 44 flow contacts between tourism network nodes. In the selected 9 nodes, there are tourism flow gather contact and spread between each tourism flow node and other 4.89 nodes on average. The standard deviation relatively smaller, suggesting that the flow gather and distribute strength of every key tourist cities is not too big. The average number of each key cities is 12.67 in tourism network acts as a mediator. The standardized value gap of outgoing and introverted close to the centrality is not big. From the standard deviation of different indicators, we can see that within the tourism flow node, the outgoing close to the centrality and mediation centrality are extremely unbalanced in tourism network. The standard deviation respective are 8.19,8.67 and 6.94. From the indicators of node centrality of each tourist cities in table 1, there are some features in space associated network as follows:

Tab. 1 Node Characteristics of Inbound Tourism Network of Key Toutist Cities Henan Province

\begin{tabular}{|c|c|c|c|c|c|c|c|c|}
\hline \multirow{2}{*}{$\begin{array}{l}\text { Key Toutist } \\
\text { Cities }\end{array}$} & \multicolumn{2}{|c|}{ Degree of centrality } & \multicolumn{2}{|c|}{ Close centrality } & \multirow{2}{*}{$\begin{array}{c}\text { Intermediation } \\
\text { centrality }\end{array}$} & \multicolumn{3}{|c|}{ The Structural Hole } \\
\hline & Inward & Outward & Inward & Outward & & Efficiency & Productiveness & Disciplinary \\
\hline Zhengzhou & 8 & 8 & 81.53 & 83.61 & 28.25 & 6.43 & 0.66 & 0.44 \\
\hline Luoyang & 5 & 8 & 62.17 & 64.82 & 19.53 & 5.71 & 0.63 & 0.62 \\
\hline Kaifeng & 4 & 4 & 57.26 & 59.15 & 15.67 & 3.55 & 0.61 & 0.78 \\
\hline Anyang & 4 & 3 & 57.26 & 58.37 & 10.08 & 2.72 & 0.52 & 0.95 \\
\hline Jiaozuo & 6 & 3 & 61.18 & 52.86 & 11.17 & 2.31 & 0.41 & 1.04 \\
\hline Nanyang & 4 & 3 & 53.35 & 54.64 & 9.62 & 1.00 & 0.20 & 1.25 \\
\hline Shangqiu & 3 & 5 & 51.29 & 55.73 & 8.15 & 1.50 & 0.26 & 1.17 \\
\hline Zhumadian & 5 & 6 & 60.07 & 63.98 & 6.17 & 1.25 & 0.31 & 1.21 \\
\hline Pingdingshan & 5 & 4 & 61.22 & 61.79 & 5.38 & 1.02 & 0.29 & 1.23 \\
\hline Sum & 44 & 44 & 545.33 & 554.96 & 114.02 & & & \\
\hline Average & 4.89 & 4.89 & 60.59 & 61.66 & 12.67 & & & \\
\hline $\begin{array}{l}\text { Standard } \\
\text { Devision }\end{array}$ & 1.37 & 1.91 & 8.19 & 8.67 & 6.94 & & & \\
\hline
\end{tabular}

(1)Through the comparison between the degree of introvert and extrovert centrality of key tourist cities, we study the central role in the tourist route in those cities. Generally speaking, the low degree of introvert centricity and the high degree of outgoing belong to inbound tourist routes opening. If both of them are high, they belong to the core situation of inbound tourist routes. Otherwise, they belong to the end of the routes. Combined with two degree of the key tourist cities of Henan performance and contrast relation, first of all, we can find that the degree of Zhengzhou's 
introversion centricity and extroversion are very high. It shows that the inbound tourism network in Zhengzhou take a central position as well as it is a beginning and ending city in inbound tourist routes in Henan. Besides, it is the inter point and the exter point and the cent of gather and spread in Henan. Zhengzhou is the national transport hub of Henan. Jing-Guang and Longhai railway intersection here, the embryonic of “米”railway has already formed. It has the largest passenger way at the airport, is a foreign-related hotel up to the most concentrated area of Henan. At the same time, it has the first national 5A scenic spot, the world heritage sites and is known at home and abroad. Shao Lin Temple and Xinzheng(The hometown of Yellow Emporer and Xuanyuan) is the main destination to visit relatives and friends. So Zhengzhou has plated an important distribution function in inbound tourism in Henan. Its degree of centricity is very high. Secondly, Luoyang, Shangqiu and Zhumadian are all belong to the end point location of inbound tourism on the account of this cities are all located in the edge of Henan. But they are all in the important node of traffic location, especially for the tourists who come from Taiwan, Hong Kong and Macao. Zhengzhou may be the starting point of the inbound tourism in Henan. And those cities have a special function. Like Luoyang, it is popularity in Henan which has the most national 5A scenic spots and the earliest world heritage sites. So, to a large extent, Luoyang is regarded as the end of inbound tourism in Henan.

(2)From introversion close centricity and extroversion close centricity, we can find that Zhengzhou is closely near centricity was located in the right portal of inbound tourism in Henan. It shows that from the beginning of the city of inbound tourism flow can easily reach other inbound tourism cities. And the other nodes of tourism flow can easily access to this nodes. Moreover, duo to the popularity and the advantage of high quality tourism resources, the tourism flow of Luoyang is accessible from other cities. Therefore, its extroversion reached the same level as Zhengzhou. But as for the introversion, due to it is not far from Zhengzhou, so most inbound tourists of other cities will arrived in Zhengzhou firstly, then to Luoyang. So, its introversion centricity may slightly imperfect.

(3)Inbound tourism network in the mediation of the key tourist city of Henan province mind value between 5.38 and 28.25. The standard deviation (6.94) higher than average(4.89), but the gap is not big. It shows that inbound tourism in Henan network has a certain gap between each nodes but the gap is not huge. Zhengzhou will appear on other tourist cities in pairs as the key intermediate node.

(4)For all centricity index performance, the lower key tourist cities such as Zhu Madian, Pingdingshan, Shangqiu and Nanyang, they have less contact with other cities. Sometimes become the jumping point of inbound tourism flow line. Many inbound tourism directly in regional flow between two cities without going through those nodes. It not has too much mediation influence to other cities, basic at the edge of the inbound tourism flow network. From the indicator of structural hole model, Zhengzhou and Luoyang have a higher level and is can not replace. Inbound tourism flow relationship involved in different node cities. However, due to this nodes which occupy the position of structural hole has no other nodes can replace, they form a stronger "jams" phenomenon of inbound tourism flow. Therefore need to strengthen travel flow transport function. At the same time, Zhengzhou and Luoyang occupy the key position in inbound tourism network structure make they win more opportunities in regional tourism resources and the configuration of the government's area propaganda.

The Overall Network Structure of Inbound Tourism in Key Tourist Cities. Using the network density index, Henan province key tourist cities tourism spatial network density is 0.61 ; a tourist flow network composed of 9 key tourist cities with the 72 largest number of connection in theory, but in reality the binding number is 44 . By comparison, the density of inbound tourism flow network is higher and the average connection between tourism network nodes is also more. But the function of tourism network needs further optimization. At this stage, Henan province key tourist city tourism destination network is formed in Zhengzhou, Luoyang as the leading factor, other key tourist city as auxiliary. The tourism flow relationship between Zhengzhou, Luoyang and other key tourist city tourist flow are closely, especially in Zhengzhou. Other key tourist city link also showed 
the medium level; the gap of regional tourism network density is bigger. Gradually was formed: Zhengzhou as the center, radiation 200KM tourism destination network space. In the linear structure in three, the tourist route which formed by Zheng Bian, Luo three nodes has the obviously characteristics. The tourist spatial behavior of inbound tourism flow of Henan province activities mainly concentrated in a limited city with high grade and tourism resources, rarely visit all the city of Henan Province, so the inbound tourism destination is not only have the coordination and integration of tourism network, but more importantly is the competition between nodes in key tourist cities which resulting in the "invisible" state of some nodes in the regional network.

Using the centricity indicator, got the indicator value of inbound tourism network in Henan Province, the inward and outward degree of centricity were $47.25 \%$ and $39.18 \%$, inward and outward toward the centricity were $48.46 \%$ and $41.22 \%$. According to this, we can see that the inward centricity is all bigger than outward centricity. In addition, the intermediary centricity is $21.72 \%$. Overall, both the degree of centricity and close centricity of inbound tourism network of key tourist cities are at a high level which shows that the inbound tourism flow network has very strong imbalance of the intermediary center. The relative value of mediation centricity is lower, indicating that most of the nodes in the network is connected through the core node and other nodes, the most of the key tourist cities node connectivity needs to further improve.

\section{Conclusion}

Through using social network analysis method, we carry on a related research of inbound tourism spatial correlation network's structural characteristics of the key tourist cities of Henan under the macro-scale, there are some conclusions as the following:

(1)Inbound tourism the key tourist city of Henan with a total of 44 on the tourism flow relationship between network nodes. Each of the key tourist cities exist between an average 4.89 in a tourist city with other tourist flow of agglomeration and diffusion. And acts as mediator in inbound tourism network number to an average of 13.69 times.

(2)The density of overall network structure is higher in inbound tourism of the key tourist cities of Henan. But there is not balanced. Key tourist cities inbound tourism's development has further room to improvement on the collaborative.

(3)The node position and role in inbound tourism space network of key tourist cities of Henan is imbalance. In general, the higher grade, the less quantity. It is the representation of a geographical space hierarchy. This grade system is mainly due to the formation of inbound tourism flow distribution function. The node's inbound tourism spatial accessibility and inbound tourism flow intermediary effect and other comprehensive effect. With the reform and development of area, node level enhances unceasingly. The spatial competition of nodes is more and more intense. At the same time, because of three comprehensive effect of node tourist cities inbound tourism development: the internal force (urban tourism infrastructure, the development of high quality resources, a good spread of tourism image), the external pulling force(tourists demands) and external thrust driving force(national macro policy). The requirement of node development conditions of the higher grades are more rigorous which results in the number of decreasing gradually while the low level node will become one part of the network status and the number will also continue to increase according to the special advantages of itself.

\section{Acknowledgments}

This work is supported by Henan Provincial Department of Humanities and Social Sciences General Project (2017-ZZJH-493)

\section{Reference}

[1] Wu Bihu. Shanghai Urban Leisure Flow Behavior Research [J]. The Geographical Journal, 1994, 49 (2):117-127. 
[2] Niu Yefei, Xie Libo, Liu Chunfeng. The Space-time Distribution Characteristics and the Control Counter Measures of Beijing Tourism Passenger Flow [J]. The Geographical Research, 2005, 24(2):283-292.

[3] Yang Xingzhu, Gu Chaolin, Wangqun. Nanjing's tourist flow network structure building [J]. The Geographical Journal. 2007, 62(6): 609-620.

[4] Zhu Wu Qitao. The Scale of Provinces and the Major Tourism Cities in China [J]. The Geographical Journal, 2005, 60(6): 919-927.

[5] Chenhao, Lulin, Zhang Jinhe, etc. The Tourism Spatial Structure and Optimization Analysis of the Pearl River Delta Urban Agglomerations [J]. The Geographical Science, 2008, 28(1): 113-118.

[6] MaYaofng, Li Tianshun, Liu Xinping. Chinese Inbound Tourism Research [J]. Beijing: Science Press, 1999.

[7] Zhanghong, Li Jiuquan. Guilin overseas tourists structure characteristics and space-time dynamic model research [J]. The Geographical Science, 2000, 20(4): 350-354.

[8] Liu Hongying, Ma Yaofeng. The West Gradient shift Characteristics Research of Beijing Inbound Tourism Flows [J].Urban Problems, 2008(5):59-63.

[9] ZhangYouyin, MaYaofeng, Ma Hongli, etc. The Balance Transfer Regularity Study of Beijing Inbound Converging Diffusion Tourism Flow [J]. Travel Journal, 2009, 24(12):31-35.

[10]WangYongming, MaYaofeng, Wang Meixia. The Spatial Diffusion Characteristics and Paths of Beijing Inbound Tourism Flow [J]. Economic Geography, 2011, 31(6): 1019-1024.

[11]WangYongming, MaYaofeng, Wang Meixia. The Spatial Field Effect of the Provinces in Yangtze River which Influenced by Shanghai Inbound Tourism Flow [J]. Economic Geography, 2010, 30(5): 854-858.

[12]Wu Jinfeng, Pan Xuli. The Analysis of Network's Structure of Inbound Tourism Flow in Beijing and Shanghai [J]. The Geographical Science, 2010, 30(3): 370-376.

[13]Ding Xusheng, Li Yongwen. The Hierarchical Structure Analysis of Henan Inbound Tourism Flow Based on the Fractal Theory [J]. Henan Science, 2011, 41(6): 605-608.

[14]ZhaoJunyuan, Du Xiaomeng, Li Xiaoli, Shang Zhipeng. The Space-time Evolution Research of Henan Inbound Tourism Flow [J]. The Forum of Economic Management in Western China, 2012, 23(4): 77-82.

[15]Zhan Xinhui, MaYaofeng, LiuJunsheng. A Research of Inbound Tourism Flow's Coupling Coordination Degree and the Regional Economic Development-Taking Henan as an Example [J]. Henan Science, 2013, 31(6):913-919.

[16]Meng Lijuan,. A Research of the Influent Factors of the Tourist Flow and Destination Coupling-Taking Zhengzhou, Kaifeng and Luoyang as an Example [J]. Management Engineer, 2014, 23(6): 54-59.

[17]Liujun. Introduction to Social Network Analysis [M].Beijing: Social Sciences Academic Press, 2004, 121-122.

[18]Chang P L, Shih H Y. Comparing patterns of intersectional innovation diffusion in Taiwan and China: network analysis [J]. Technovation, 2005, 25(2):155-169. 